\title{
Carcinoma de células de Merkel em extremidade inferior
}

\author{
Merkel cell carcinoma in lower end
}

Marcelo Wilson Rocha Almeida ${ }^{1}$; Catiucia Carneiro Lopes²; Hiram Larangeira de Almeida Junior ${ }^{3}$; Luis Eugênio Costa ${ }^{4}$

INTRODUÇÃO

O Carcinoma de Células de Merkel (CCM) é uma neoplasia cutânea rara e sua incidência aumentou de 0,15 para 0,44 casos em 100.000 na população entre 1986 e $2001^{1}$. Existe predileção pelo sexo masculino, com uma razão homem/mulher de 1,4:1 a 2,3:1. A maioria dos pacientes apresenta-se com uma média de idade de 66 anos ao diagnóstico. É uma neoplasia incomum em indivíduos da raça negra $(0,023$ casos/ 100.000 habitantesano) comparado com brancos $(0,26$ casos $/ 100.000$ habitantes-ano) e a maioria ocorre em áreas da pele expostas ao sol (cabeça, pescoço e extremidades)². Existe pouco menos de 600 casos de CCM na literatura, apresentando-se, clinicamente, como uma lesão nodular, de coloração vermelha-azulada e de crescimento rápido³.

A etiologia ainda é desconhecida, e uma hipótese sugere que o tumor origina-se de uma célula-tronco totipotencial imatura que adquire características neuroendócrinas durante sua transformação maligna ${ }^{4}$.

O presente relato apresenta um novo caso de carcinoma de células de Merkel em extremidade, tratado com ressecção local, radioterapia adjuvante e, no terceiro mês de pós operatório, foi submetido à linfadenectomia inguinal radical .

\section{RELATO DO CASO}

MAVP, 74 anos de idade, branca, viúva, natural e residente em Pelotas/RS, procura o ambulatório de Cirurgia Geral por apresentar lesão vegetante no joelho esquerdo, dolorosa ao toque, com aproximadamente $4 \mathrm{~cm}$ de diâmetro. Refere que há quatro anos sofreu trauma contuso no local, quando, então, percebeu o surgimento de pequena tumoração que há um ano vem aumentando de tamanho gradativamente (Figura 1). Relata histerectomia abdominal total por adenocarcinoma de endométrio pouco diferenciado, grau 1 (estadiamento T1 NxM0), atingindo terço interno do útero há oito meses, sendo submetida a seis sessões de braquiterapia no Hospital Santa Rita em Porto Alegre. Refere internação prévia para tratamento de celulite periorbitária estreptocóccica há três anos. Nega outras doenças ou uso de medicação. Apresenta alergia à penicilina e história familiar de neoplasia hepática e pulmonar.

Foi realizada biópsia incisional que revelou neoplasia maligna indiferenciada (Figura 2). Os exames de estadiamento (Rx tórax, US abdominal total e laboratório)

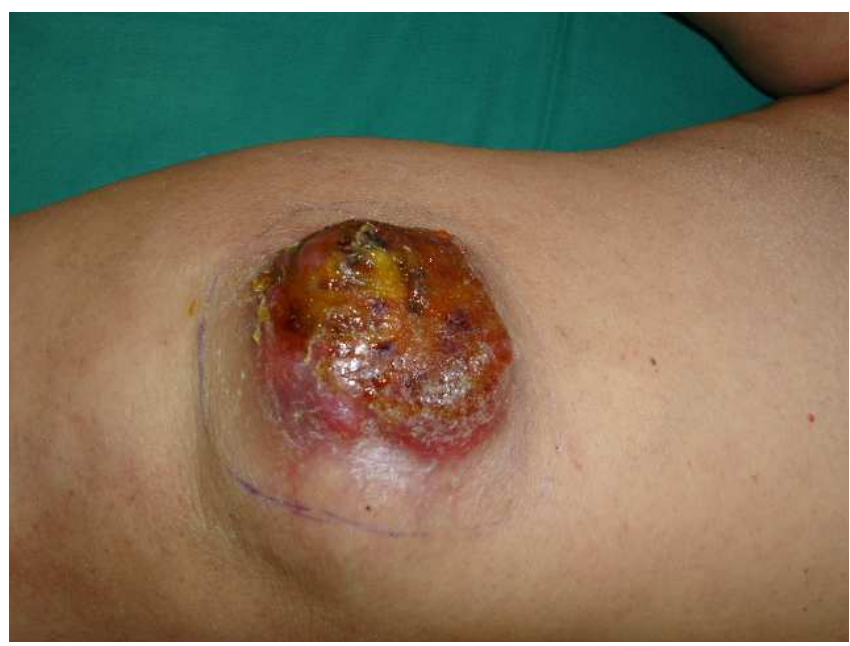

Figura 1 - a) tumoração no joelho.

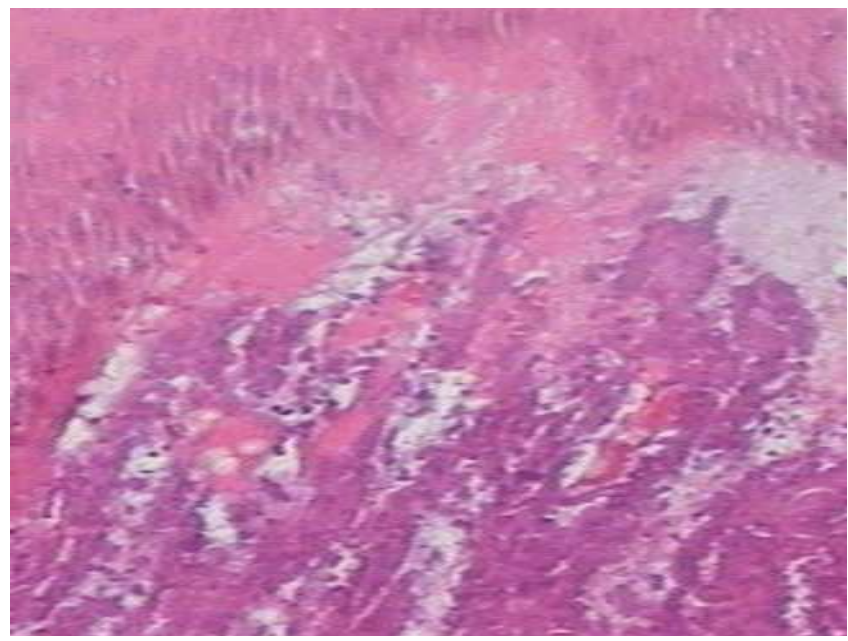

Figura 2 - Cordões de células neoplásicas na derme papilar (HE 100x).

Trabalho realizado no Serviço de Cirurgia Geral do HUSFP, Pelotas, RS, Brasil.

1. Cirurgião Plástico formado no Instituto Ivo Pitanguy e Membro da Sociedade Brasileira de Cirurgia Plástica; 2. Médica pela Universidade Católica de Pelotas (UCPel); 3. Professor Adjunto de Dermatologia da Escola de Medicina da UCPel; 4. Professor Adjunto da Clínica-Cirúrgica da Escola de Medicina da UCPel. 
não evidenciaram nenhuma alteração. Foi, então, submetida à exérese cirúrgica do tumor associada à confecção de retalho cutâneo. A paciente evoluiu favoravelmente recebendo alta no primeiro dia de pósoperatório, sendo encaminhada para radioterapia adjuvante.

O resultado do exame anátomo-patológico demonstrou neoplasia maligna indiferenciada, composta por células epiteloides com foco de necrose com margem profunda livre. Não se exclui lesão metastática, sendo necessário complementar com estudo imunoistoquímico. Foi, então, solicitado o exame que evidenciou Carcinoma Neuroendócrino Primário de Pele (Tumor de Merkel), contudo não se detecta expressão de cromogranina, o que pode ocorrer em $36 \%$ dos casos, tendo como anticorpos positivos a Citoqueratina 20 (clone Ks 20.8) (dot-like) e Queratina (AE1/AE3) (dot-like paranuclear) (Figuras 3A e B).

A paciente foi diagnosticada como portadora de doença no estádio I, sendo submetida à radioterapia no joelho esquerdo com 46 aplicações, cada uma de 180GY.

No terceiro mês após a operação apresentou nodulação na região inguinal esquerda dolorosa à palpação, sendo submetida à biópsia incisional que evidenciou linfonodo com metástases de neoplasia maligna indiferenciada. Os exames de estadiamento (Rx tórax, TC abdominal total e laboratório) não evidenciaram nenhuma alteração. Foi, então, submetida à linfadenectomia inguinal radical. A paciente evoluiu favoravelmente recebendo alta no quarto dia do pós-operatório, sendo encaminhada para continuação da radioterapia adjuvante e avaliação para quimioterapia. O exame anátomopatológico demonstrou linfonodos com metástases de neoplasia maligna indiferenciada, demonstrando a progressão da doença.

\section{DISCUSSÃO}

Os pacientes com CCM apresentam-se tipicamente com um nódulo de rápido crescimento, indolor, firme, vermelho-azulado, medindo aproximadamente $2 \mathrm{~cm}$ de diâmetro. A lesão é mais comumente encontrada em áreas expostas ao sol, como a cabeça e pescoço ${ }^{1-4}$, acometendo a extremidade inferior em apenas $16,8 \%{ }^{4}$ dos casos.

A maioria dos pacientes apresenta doença localizada quando do diagnóstico, entretanto, o CCM é uma doença que apresenta alto índice de recidiva local (20-75\%), metástases em linfonodos regionais (31-80\%) e metástases à distância (26-75\%). Apresenta mortalidade de aproximadamente $65 \%^{3}$. Quando desenvolve doença sistêmica os sítios mais comuns são o fígado, pulmão, ossos e o cérebro 4 . Aproximadamente, $42 \%$ dos pacientes com CCM tiveram alguma neoplasia maligna prévia ${ }^{1,3}$

A elaboração diagnóstica inicial deve incluir uma radiografia de tórax para excluir um tumor pulmonar primário, dada sua semelhança histológica com o carcinoma de pequenas células ${ }^{2}$.

O diagnóstico é baseado na biópsia da lesão, que deve revelar um tumor dentro da derme com extensão para o tecido subcutâneo. A epiderme, derme papilar e estruturas anexas não estão usualmente envolvidas. A imuno-histoquímica revelará marcadores epiteliais, como a citoqueratina 20 e neuroendócrino, fazendo a sua diferenciação ${ }^{1,2,4}$.

O tratamento inicial consiste em uma excisão cirúrgica com margens negativas de $2 \mathrm{~cm}^{1}$. Não existem evidências de que margens livres reduzam índices de recorrência e/ou sobrevida. A indicação de linfadenectomia profilática devido à alta probabilidade de metástases linfonodais é discutível, pois, apesar de ocorrer um maior

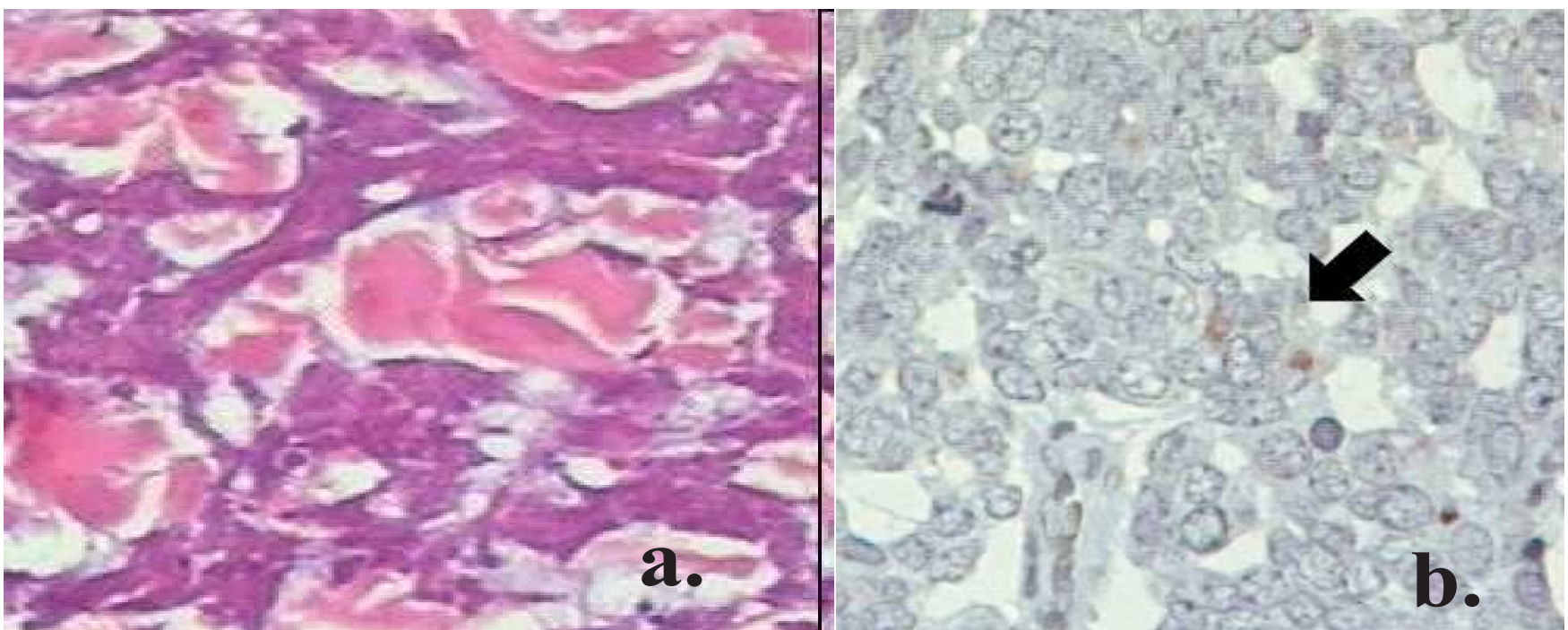

Figura 3 - a) formação de trabéculas na derme profunda (HE 100x); b) imuno-histoquímica com células positivas (seta) para citoqueratina 20 (imunoperoxidase 400x). 
controle locorregional da doença, não apresenta melhora na sobrevida'.

Não existem evidências de que o tamanho da lesão ou margens livres reduzam índices de recorrência e/ ou sobrevida ${ }^{3}$. Entretanto ${ }^{5}$, em uma revisão dos CCM constatou que o tamanho do tumor, o sexo (masculino), as metástases regionais e à distância no diagnóstico ou durante o seguimento apresentam um mal prognóstico.

A radioterapia adjuvante é frequentemente recomendada e está associada com diminuição da recorrência local, locorregional e com aumento na sobrevida. Todavia, a quimioterapia adjuvante não tem sido recomendada, não obstante o CCM ser um tumor quimiossensível ${ }^{4}$.

Apesar de a maioria dos pacientes apresentarem doença limitada à admissão, aqueles que possuírem diagnósticos e/ou terapêutica tardios têm sobrevida semelhante aos pacientes portadores de melanoma maligno. Daí a importância de fazermos um precoce diagnóstico diferencial desta importante malignidade cutânea com as demais lesões que encontramos na prática médica diária.

\section{A B S S T R A C T}

Merkel Cells Carcinoma is a rare cutaneous neoplasia. Studies revealed an increase in the occurrence from 0.15 to 0.44 cases for every 100.000 inhabitants between 1986 and 2001. Around 50\% of the patients, eventually, develop systemic disease, being the most common sites the liver, the bones and the brain. The etiology is still unknown. The present study presents a new case of Merkel cells carcinoma in extremity, treated with local resection and adjuvant radiotherapy.

Key words: Carcinoma, Merkel cell. Skin neoplasms. Lower extremity. Radiotherapy. Drug therapy.

\section{REFERÊNCIAS}

1. Duprat JP, Landman G, Salvajoli JV, Brechtbühl ER. A review of the epidemiology and treatment of Merkel cell carcinoma. Clinics. 2011;66(10):1817-23.

2. Eng TY, Boersma MG, Fuller CD, Goytia V, Jones WE 3rd, Joyner $M$, et al. A comprehensive review of the treatment of Merkel cell carcinoma. Am J Clin Oncol. 2007:30(6):624-36.

3. Kaae J, Hansen AV, Biggar RJ, Boyd HA, Moore PS, Wohlfahrt J, et al. Merkel cell carcinoma: incidence, mortality, and risk of other cancers. J Natl Cancer Inst. 2010;102(11):793-801.

4. Becker JC, Kauczok CS, Ugurel S, Eib S, Bröcker EB, Houben R. Merkel cell carcinoma: molecular pathogenesis, clinical features and therapy. J Dtsch Dermatol Ges. 2008;6(9):709-19.

5. Pectasides $D$, Pectasides $M$, Economopoulos $T$. Merkel cell cancer of the skin. Ann Oncol. 2006;17(10):1489-95.
Recebido em 05/03/2007

Aceito para publicação em 05/04/2007

Conflito de interesse: nenhum

Fonte de financiamento: nenhum

\section{Como citar este artigo:}

Almeida MWR, Lopes CC, Almeida Júnior HL, Costa LE. Carcinoma de células de Merkel em extremidade inferior. Rev Col Bras Cir. [periódico na Internet] 2012; 39(2). Disponível em URL: http://www.scielo.br/rcbc

\section{Endereço para correspondência:}

Marcelo Wilson Rocha Almeida

E-mail: contato@drmarceloalmeida.com.br 